\title{
Ocular toxocariasis simulating a retinal hamartoma. A case report
}

\section{Toxocariasis ocular simulando un hamartoma retiniano. Reporte de un caso}

\author{
Luis R. Michel-Espinoza ${ }^{1 *}$, Belina Arias-Cabello², Daniel Moreno-Páramo³, and M. Estela Arroyo-Yllanes² \\ 1Ophthalmology Department; ${ }^{2}$ Strabismus and Pediatric Ophthalmology Department; ${ }^{3}$ Retina and Vitreous Department. Hospital General de México \\ Dr. Eduardo Liceaga, Mexico City, Mexico
}

\begin{abstract}
Case report: The case concerns a 6 year-old girl who refers a 6-month history of decreased visual acuity in the right eye. The only relevant data during interrogation was contact with dogs. The initial diagnosis was a retinal hamartoma. The patient was studied with complete blood count, blood chemistry, magnetic resonance imaging, and $A$ and B-scan ultrasonography. Anti-Toxocara canis antibodies were measured (IgG $24.5 \mathrm{U}$, normal range 0-9 U; IgM and IgA $<2.5 \mathrm{U}$ within normal range). Discussion: After a comprehensive evaluation that ruled out a retinoblastoma, along with laboratory tests and imaging findings, we established a diagnosis of a central granuloma with centripetal vitreoretinal contraction caused by ocular toxocariasis.
\end{abstract}

Keywords: Toxocariasis. Hamartoma. Diagnosis. Retinoblastoma.

\section{Resumen}

Caso clínico: Paciente de sexo femenino, de 6 años, que acudió refiriendo baja visual del ojo derecho de 6 meses de evolución; antecedente de contacto con perros. El diagnóstico clínico inicial fue el de un hamartoma retiniano. Se realizó un abordaje con estudios de biometría hemática, química sanguínea, resonancia magnética de cráneo y ultrasonido en modo $A B$. Se solicitó posteriormente determinación de anticuerpos para Toxocara cani (inmunoglobulina [lg] G $24.5 \mathrm{U}$, valores de referencia 0-9U; IgM e IgA < 2.5 U, dentro de parámetros). Discusión: Tras haber realizado el abordaje de la paciente de manera integral descartando un retinoblastoma, sumado a los hallazgos clínicos y de laboratorio, se establece diagnóstico final de granuloma central por toxocariasis con contracción vitreorretiniana centrípeta. La paciente se encuentra bajo vigilancia y seguimiento en el hospital.

Palabras clave: Toxocariasis. Hamartoma. Diagnóstico. Retinoblastoma.

Correspondence:

*Luis R. Michel-Espinoza

Vicente Suarez 38, Int 5

Hipódromo Condesa, Del. Cuauhtémoc Date of reception: 24-05-2020

CP 06170, Mexico City, Mexico Date of acceptance: 15-09-2020

E-mail: Irodrigom14@gmail.com

DOI: 10.24875/RMOE.M21000198

Available online: 05-11-2021

Rev Mex Oftalmol (Eng). 2021;95(6):277-280

www.rmo.com.mx

2604-1731/@ 2020 Sociedad Mexicana de Oftalmología. Published by Permanyer. This is an open access article under the CC BY-NC-ND license (http://creativecommons.org/licenses/by-nc-nd/4.0/). 


\section{Introduction}

Ocular toxocariasis is a pathology with different clinical presentations; the type of clinical presentation is somewhat related to age. The diagnosis is essentially clinical and it follows a comprehensive approach.

\section{Clinical case}

This is the case of a 6-year-old female patient who came to our hospital with a 6-month history of decreased vision in the right eye. The patient did not report associated symptoms, and upon questioning, the only relevant history was contact with dogs (puppies), in addition to coming from a rural area.

The patient was managed by the pediatric ophthalmology and strabismus departments, as well as by the retina and vitreous department. On examination, visual acuity in the right eye was counting fingers at $30 \mathrm{~cm}$, and in the left eye it was 20/20; the anterior segment of both eyes showed no alterations and preserved pupillary reflexes. A right monocular esotropia of less than 10 prismatic diopters was observed. The posterior segment of the right eye had a lesion of approximately 2 disc diameters, pearly in color, raised, with pigmentary changes and surrounded by fibrous tissue, with retinal vessels radiating from the margin of the optic disc and the presence of adjacent subretinal fluid. Furthermore, the borders of the papilla could be partially observed behind the described lesion (Fig. 1). There was no evidence of inflammation in the vitreous cavity. The left eye was normal. Initially we diagnosed a retinal hamartoma, with the indication to rule out a retinoblastoma.

As an approach protocol for a probable intraocular tumor, the patient was admitted for evaluation and to diagnose syndromes associated with a hamartoma. No clinical data suggested neurofibromatosis or other phakomatosis. An AB-mode ultrasound of the right eye showed a homogeneous raised lesion in the posterior pole, of medium to high reflectivity (Fig. 2). An MRI of the skull was performed with projection to the orbits, excluding any other ocular, orbital or brain tumor. The laboratory tests (hematology, blood chemistry) within normal parameters along with the imaging studies ruled out a retinoblastoma (Fig. 3). We requested antibodies against Toxocara (considering a diagnosis of ocular toxocariasis), which were positive for Toxocara cani (immunoglobulin [lgG] $24.5 \mathrm{U}$, reference values 0-9 U; $\lg \mathrm{M}$ and $\lg \mathrm{A}<2.5 \mathrm{U}$, within normal values).

Finally, considering the history of contact with dogs, added to the clinical and laboratory findings, we

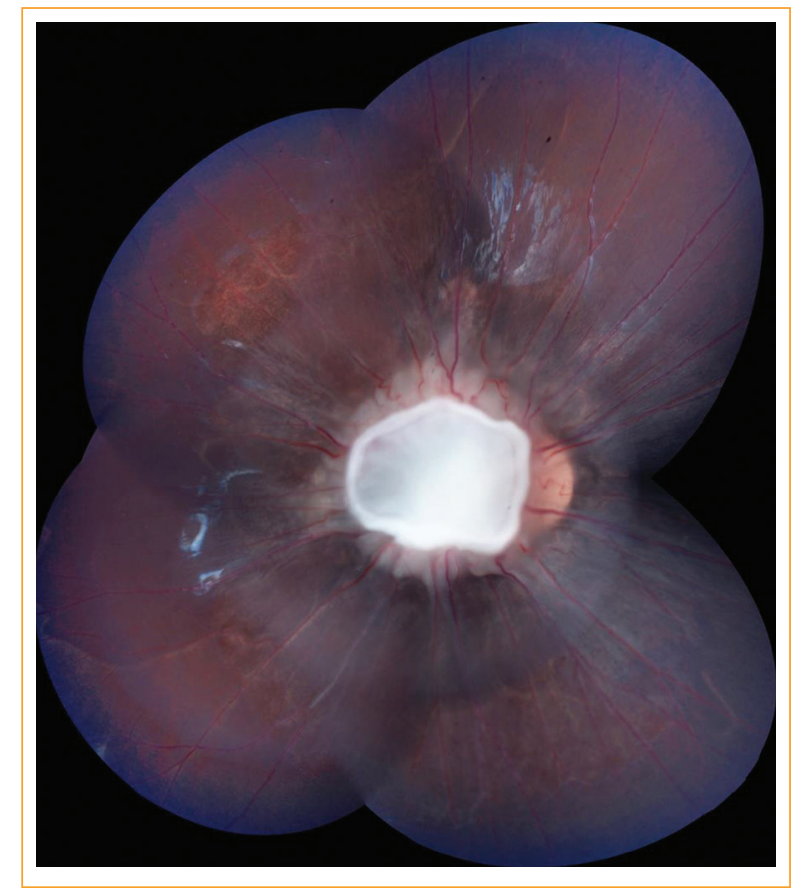

Figure 1. Clinical photography of the right eye fundus.

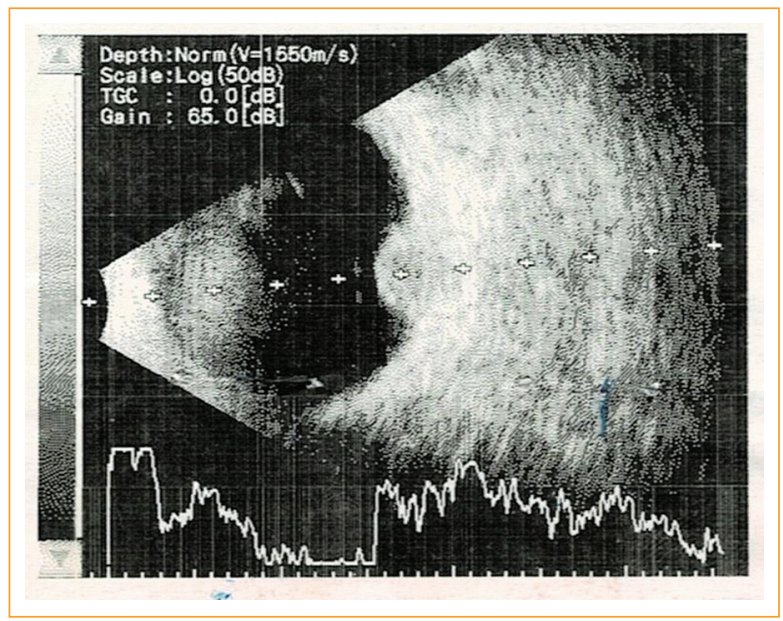

Figure 2. A- and B-mode ultrasound of the right eye.

established a diagnosis of a central granuloma due to toxocariasis with centripetal vitreoretinal contraction. The patient is under follow-up, and warning signs were explained both to her and her relative.

\section{Discussion}

Toxocariasis is an infection caused by the nematode Toxocara canis and less commonly by other roundworms, such as Toxocara cati. The systemic disease is 


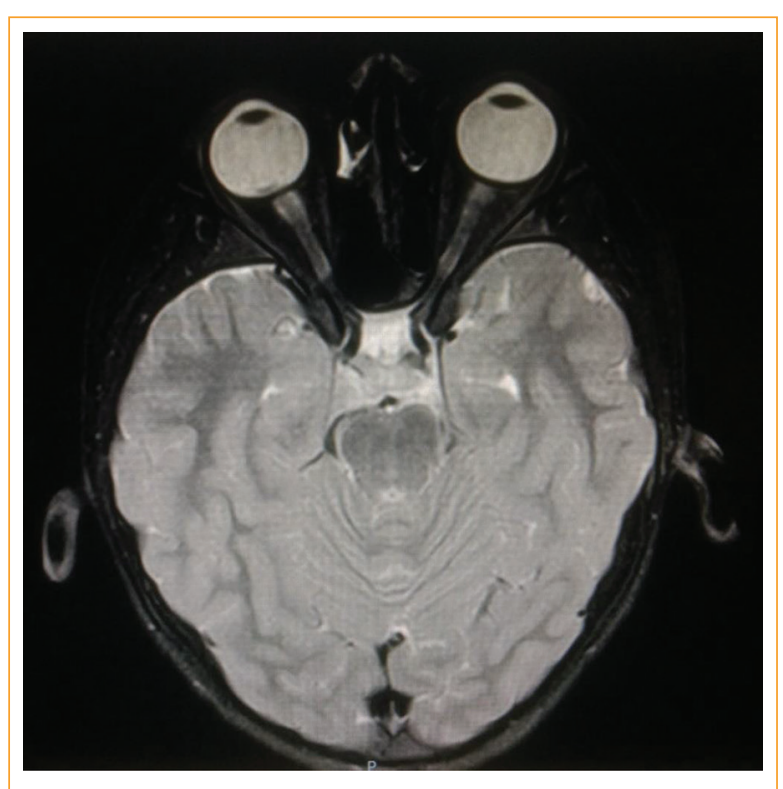

Figure 3. Magnetic resonance imaging of the orbits with fat suppression.

called visceral larva migrans and is characterized by generally affecting children 6 months to 4 years of age and manifesting with eosinophilia, fever, paleness, anorexia, hepatomegaly, and transitory pulmonary infiltrates. Ocular toxocariasis is rare in adults, but in children it is considered an important cause of visual loss that must be ruled out. The initial approach is relevant, since in some cases the presence of a retinoblastoma or another retinal tumor should be considered, especially when the clinical findings are not classical and therefore imaging studies, such as MRI, are justified to properly evaluate the patient 1 .

Ocular toxocariasis has three classic forms of presentation: peripheral granuloma, posterior pole granuloma and chronic endophthalmitis. Each of them is related to an age of presentation: endophthalmitis occurs mainly from 2 to 9 years, posterior pole granuloma from 6 to 14 years, and peripheral granuloma can occur during childhood, although it is more frequent in young people and adults ${ }^{2}$. Our patient had a posterior pole granuloma, which corresponds to her age. In addition, a data that guided the diagnosis was the history of contact with puppies, which are one of the definitive hosts due to the process of defecation of the parasite's eggs. Antibodies to Toxocara can be an aid to diagnosis; using the enzyme-linked immunosorbent assay (ELISA) method, the antibodies have a specificity of $92 \%$ and a sensitivity of $78 \% \%^{1,3}$. Antibody titers are considered positive even with values $>1: 8^{1.3}$. It is important to note that the positivity of the antibodies does not allow to confirm the causal relationship with the ocular findings, since seroprevalence can be high even in patients without manifestations of the disease ${ }^{4}$. A study in a Mexican population describes a seroprevalence of $10.6 \%$ in a series of 288 samples taken from children $^{5}$, which indicates a high seroprevalence in this population group. Therefore, antibodies do not establish the diagnosis, but may be a tool in the context of prior contact if clinical findings strongly suggest a Toxocara infection. It should be mentioned that eosinophilia is not a characteristic finding and that it is usually present mainly in systemic infection ${ }^{1,6}$.

The esotropia of the patient speaks of a chronic condition; however, we think that due to the magnitude of the deviation (<10 prismatic diopters) and the questioning, there is the possibility that the patient had a good vision previously in the affected eye, suggesting an acquired pathology. Regarding the aspect of the lesion, we consider that the vessels radiating from the optic disc are secondary to the fibrosis process generated by the granuloma, due to a traction phenomenon that can be observed in Toxocara granulomas, and we were also able to partially observe the papilla behind the lesion. It should not be overlooked that the characteristics of the lesion can also lead to a congenital alteration.

An astrocytic hamartoma or astrocytoma of the retina can manifest very similarly, and that was our initial diagnosis. Retinal astrocytoma usually has a location near or on the optic nerve, and it can progress to calcifications and vitreous seeding, so it can simulate a retinoblastoma ${ }^{7}$. Another important point that should be mentioned in our case is that no calcifications were observed by ocular ultrasound (both A- and B-modes). Retinal astrocytoma usually presents as a whitish, grayish or even yellowish lesion, slightly elevated on the retina, and the vascular changes can be important, so there may be intrinsic contraction towards the lesion and retinal traction. However, these tumors are considered quite rare and are usually associated with systemic diseases, such as tuberous sclerosis and neurofibromatosis ${ }^{8,9}$. Combined hamartoma of the retina and the retinal pigment epithelium has similar manifestations as retinal astrocytoma, such as gray or dark elevations involving the retinal pigment epithelium and may be covered with thickened gray retinal tissue, along with vascular traction ${ }^{10}$. Likewise, they are usually observed in patients with neurofibromatosis or tuberous sclerosis. We opted to establish the diagnosis of a 
central granuloma due to toxocariasis with centripetal contraction, since when observing the lesion, there are changes in the retinal pigment epithelium but not to the same degree as in a combined hamartroma of the retina and the retinal pigment epithelium. Similarly, the absence of calcifications and vitreous seeding, added to the fact that the patient did not have systemic manifestations or magnetic resonance imagingn findings that would support any phacomatosis, made us consider a Toxocara granuloma instead of a retinal astrocytoma. Also, we found in the literature images of Toxocara granulomas cases with similar findings ${ }^{4,11}$.

Regarding treatment, we decided to monitor the patient, since her clinical presentation was a chronic one and did not have intraocular inflammation. While antiparasitic treatment has been reported as successful, its use is still controversial, although it is indicated for systemic disease; therefore, we did not consider it necessary for this patient ${ }^{1,12}$.

\section{Conclusions}

Ocular toxocariasis is observed more frequently in children and should be considered in cases with a history of possible contact for infection. Likewise, it can simulate several conditions, with which a differential diagnosis must be made. The diagnosis is essentially clinical, but it can be reinforced with laboratory findings or clinical history data that support it; in some cases, the evaluation of systemic manifestations is essential to rule out other diseases.

\section{Conflicts of interest}

The authors declare no conflicts of interest.

\section{Ethical disclosures}

Protection of human and animal subjects. The authors declare that no experiments were performed on humans or animals for this study.

Confidentiality of data. The authors declare that they have followed the protocols of their work center on the publication of patient data.

Right to privacy and informed consent. The authors have obtained the written informed consent of the patients or subjects mentioned in the article. The corresponding author is in possession of this document.

\section{References}

1. Ávila M, Isaac D. Helminthic disease. En: Schachat AP, editor. Ryan's Retina. 6th ed. Philadelphia: Elsevier; 2018. p. 1685-99.

2. Infectious Ocular Inflammatory Disease. En: American Academy of Ophthalmology. Intraocular Inflammation and Uveitis, Section 9. Ed. 20142015. American Academy of Ophthalmology; 2014. p. 235-7.

3. Kwon J, Lee SY, Jee D, Cho YK. Prognosis for ocular toxocariasis according to granuloma location. PLoS One. 2018;13:1-8.

4. Sánchez-T JE, López-G JP, González-N M, Villaseca-D E, Manieu-M D Roizen-B A, et al. Prevalence of ocular lesions in children seropositive to Toxocara canis. Rev Chil Infect. 2011;28:431-4

5. Tinoco-Gracia L, Barreras-Serrano A, López-Valencia G, Tamayo-Sosa AR, Quiroz-Romero H, Melgarejo T. Seroprevalence of larva migrans of Toxocara canis and evaluation of associated risk factors among children in a Mexico-United States border region. Int J Appl Res Vet M. 2008;6:130-6.

6. Ahn SJ, Ryoo NK, Woo SJ. Ocular toxocariasis: clinical features, diagnosis treatment and prevention. Asia Pac Allergy. 2014;4:134-41.

7. Cruess AF, Sharma S. Tuberous sclerosis and the eye. En: Schachat AP, editor. Ryan's Retina. 6th ed. Philadelphia: Elsevier; 2018. p. 2438-45.

8. Cohen VM, Shields CL, Furuta M, Shields JA. Vitreous seeding from retinal astrocytoma in three cases. Retina. 2008;28:884-8.

9. Shields JA, Eagle RC Jr, Shields CL, Marr BP. Aggressive retinal astrocytomas in four patients with tuberous sclerosis complex. Trans Am Ophthalmol Soc. 2004;102:139-48

10. Shields CL, Thangappan A, Hartzell K, Valente P, Pirondini C, Shields JA. Combined hamartoma of the retina and retinal pigment epithelium in 77 cases visual outcome based on macular versus extramacular tumor location. Ophthalmology. 2008;115:2246-52.e3.

11. Visliel J, Karakas S. University of lowa Health Care. Eye Rounds.org, 2015. (Última actualización el 25 de febrero de 2015.) Disponible en: https:// webeye.ophth.uiowa.edu/eyeforum/atlas/pages/toxocara/index.htm.

12. Seong S, Moon D, Lee DK, Kim HE, Oh HS, Kim SH, et al. A case of ocular toxocariasis successfully treated with albendazole and triamcinoIon. Korean J Parasitol. 2014;52:537-40. 